\title{
The plantswoman who dressed as a boy
}

\section{The tale of the first female to sail around the world deserves a more accurate telling, says Sandra Knapp.}

$\mathrm{I}$ n 1737, the great Swedish botanist Carl Linnaeus, who established the system by which we name animals and plants today, posed in an authentic Sami costume from Lapland not realizing that it was a woman's outfit. Another case of eighteenth-century botanical cross-dressing is related in Glynis Ridley's book. French botanist Jeanne Baret dressed as a boy to gain passage on explorer Louis-Antoine de Bougainville's voyage to circumnavigate the globe.

The intrepid Baret saw more biodiversity than the notoriously stay-at-home Linnaeus, yet she is not well known. In The Discovery of Jeanne Baret, Ridley purports to resurrect her name and accomplishments. Sadly, the author does not convincingly deploy the few facts available, so the book feels more like fiction than non-fiction, a novel whose characters are real people from history.

Explorers in the eighteenth century were overwhelmingly male, so the tale of a young woman who dressed as a man to see the world has huge appeal. De Bougainville set off in 1766 on the first French circumnavigation of the globe - also the first by any nation to include a professional naturalist to record the plants and animals of new lands.

The naturalist was Philibert Commerson (or Commerçon), a friend of Voltaire and correspondent of Linnaeus. He was accompanied by Baret, a peasant woman from Burgundy who was his housekeeper and lover. Ridley weaves a tale of Baret's early life from waferthin evidence comprising a few official documents, such as birth certificates, and a book of medicinal plants attributed to Commerson, which Ridley speculates was written by Baret. She is portrayed as a 'herb-woman' whose practical knowledge was useful to Commerson - his teacher rather than his assistant.

That Baret had the guts and determination to overcome gender and class barriers is without doubt. But Ridley does both Baret and Commerson a disservice by painting the latter as a parasitic ne'er-do-well while Baret comes across as a hard-working servant. I feel that Ridley misrepresents what must have been a truly collaborative partnership in the discovery of botanical and

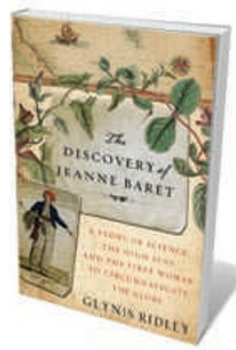

The Discovery of Jeanne Baret: A Story of Science, the High Seas and the First Woman to Circumnavigate the Globe

GLYNIS RIDLEY

Crown: 2010

304 pp. $\$ 25$ zoological wonders. Why else would Baret have stayed with Commerson in Mauritius and Madagascar after they left the expedition, only parting from him at his death in 1773 ?

How Baret concealed her gender for so long in the close confines of the ship is unclear. She must have bound her breasts, and Ridley's version has her hiding out in Commerson's cabin. Women disguising themselves as men was not unknown at the time - in 1745, Hannah Snell dressed as a man and enlisted in the British Marines, serving for five years and completing tours of India; her book The Female Soldier, published in 1750 , was hugely popular.

De Bougainville's official accounts of the voyage place the unmasking of Baret's gender in Tahiti, where the expedition stayed in April and May of 1767.

Ridley, however, consulted previously unused journals and official documents and presents a different tale - predatory, sex-mad sailors and a lone vulnerable woman left unprotected by her partner. The journal kept by the ship's surgeon François Vivès is dripping with sexual innuendo; his account of the discovery of Baret's true gender is corroborated by other diaries. Ridley weaves a story of Baret's violation and subsequent pregnancy from his coy references to "concha veneris" (the Venus shell) and to the "Jeanneton" of French folksong who loves her attackers. Vivès' account puts Baret's unmasking and violation on the shores of Papua New Guinea in June.

This makes compelling reading, but I would be more inclined to take the history seriously if Ridley had not got the scientific aspects so wrong. It is easy to check how many plants Commerson and Baret collected, and from where. Although Commerson never made it back to France before his death in Mauritius, the collections did. A search under his name in the database of plants held at the National Museum of Natural History in Paris finds 1,735 specimens and their countries of origin: 234 from Madagascar, 144 from Mauritius, 84 from Brazil and so on. Most have on them old, handwritten labels with short descriptions, perhaps jotted in the field.

Ridley maintains, for instance, that Commerson and another member of the expedition, the Prince de Nassau-Siegen, collected no plants during a short stay on Java. The database differs -50 specimens were retrieved, many of them forming the basis for new species. To highlight such inaccuracies might seem pedantic, but Ridley's story revolves around Baret struggling with heavy loads of plant presses, vials, nets and jars while Commerson swans around.

I, too, collect plants and carry paraphernalia - heavy work, but great fun. Commerson and Baret encountered a huge wealth of diversity. Commerson wrote of Madagascar:

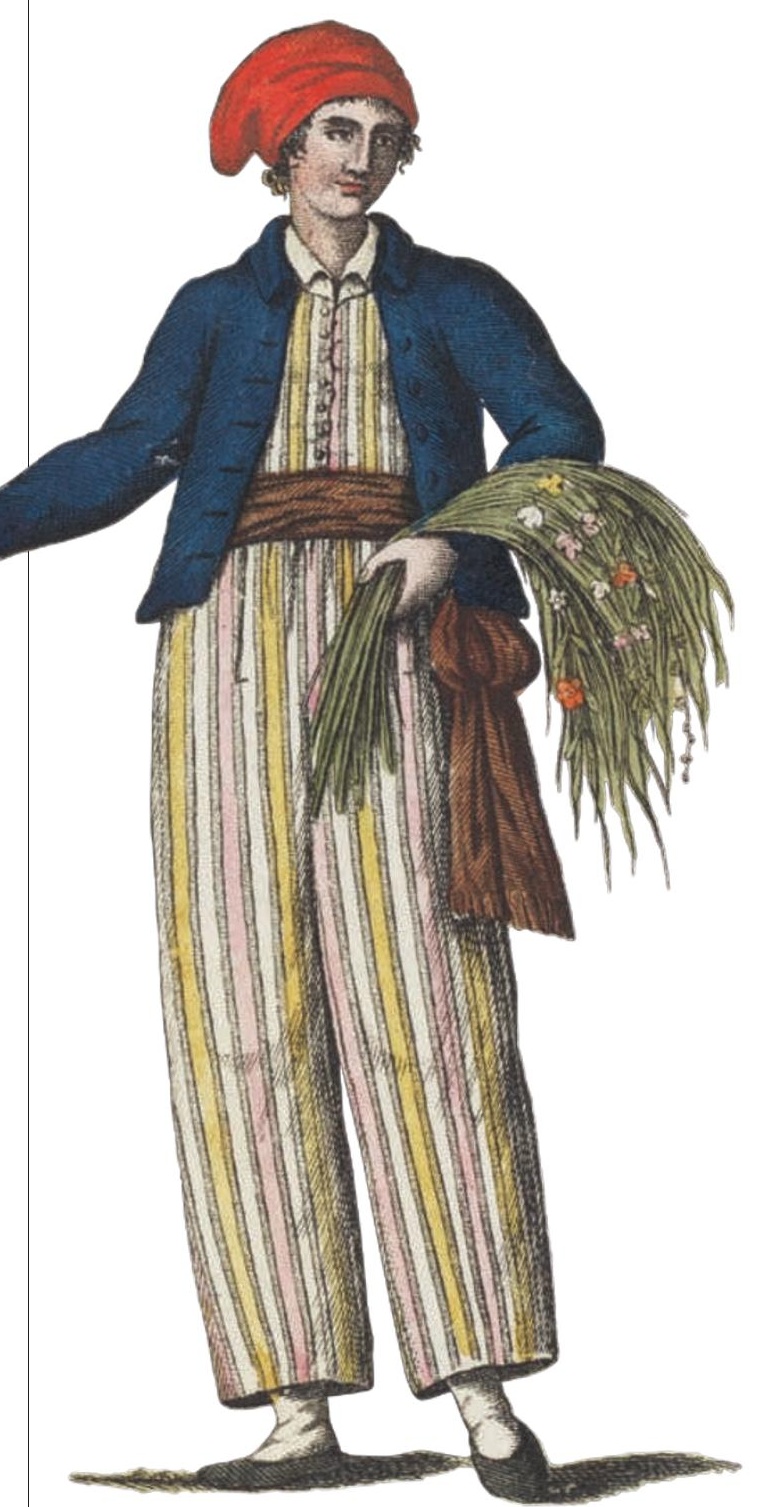

Botanist Jeanne Baret depicted en travesti. 
"I can announce to naturalists that this is the true Promised Land. Here nature created a special sanctuary where she seems to have withdrawn to experiment with designs different from those used anywhere else. At every step one finds more remarkable and marvellous forms of life."

Ridley describes how Baret discovered Bougainvillea in the forests of Rio de Janeiro using the doctrine of signatures, a medieval method by which herbalists attributed curative powers to plants on the basis of their appearance - a walnut was good for brain trouble, red things for wounds. Commerson had an ulcerating sore on his leg, so Ridley writes of Baret searching frantically for a cure, only to find it in the red bracts of Bougainvillea holding a pea-like pod that reminded her of the red-flowered runner beans from home. However, Bougainvillea does not have fruits like a pea, nor do the notes on the specimen mention any medicinal value.

In his notes, Commerson honoured high-ranking members of the expedition - its leader is commemorated in Bougainvillea, Nassau-Siegen in Nassauvia - but he did not publish these names. Bougainvillea was formally described in 1789 by Antoine Laurent de Jussieu, a French botanist who used Commerson's specimens and notes. Commerson also proposed the name Baretia for a Malagasy tree.

Ridley maintains that Commerson was an arrogant man who named things for himself. Yet the International Plant Names Index shows 119 species of flowering plants named in his honour - by others. None is noted as 'commersonii' on its original label. Commerson's Baretia was never published, not because someone wanted to do Baret down, but because it was found, on the specimen's return to Paris, that the genus already had a name.

After Commerson died, Baret married a French officer, Jean Duberna, on Mauritius and returned to France in 1774. She was awarded a state pension from 1785 in recognition of her bravery and contributions. She was not forgotten, although she never practised botany again.

Science was as collaborative then as it is now, but women's contributions were often overlooked in favour of those of male colleagues - a trend that continues today. Baret and other neglected contributors deserve recognition, but she does not need to be cast as a victim to be seen as a success, or her undoubted accomplishments overinflated. She, and women scientists in general, deserve better.

Sandra Knapp is a botanist at the Natural History Museum, London SW7 5BD, UK.

e-mail:s.knapp@nhm.ac.uk

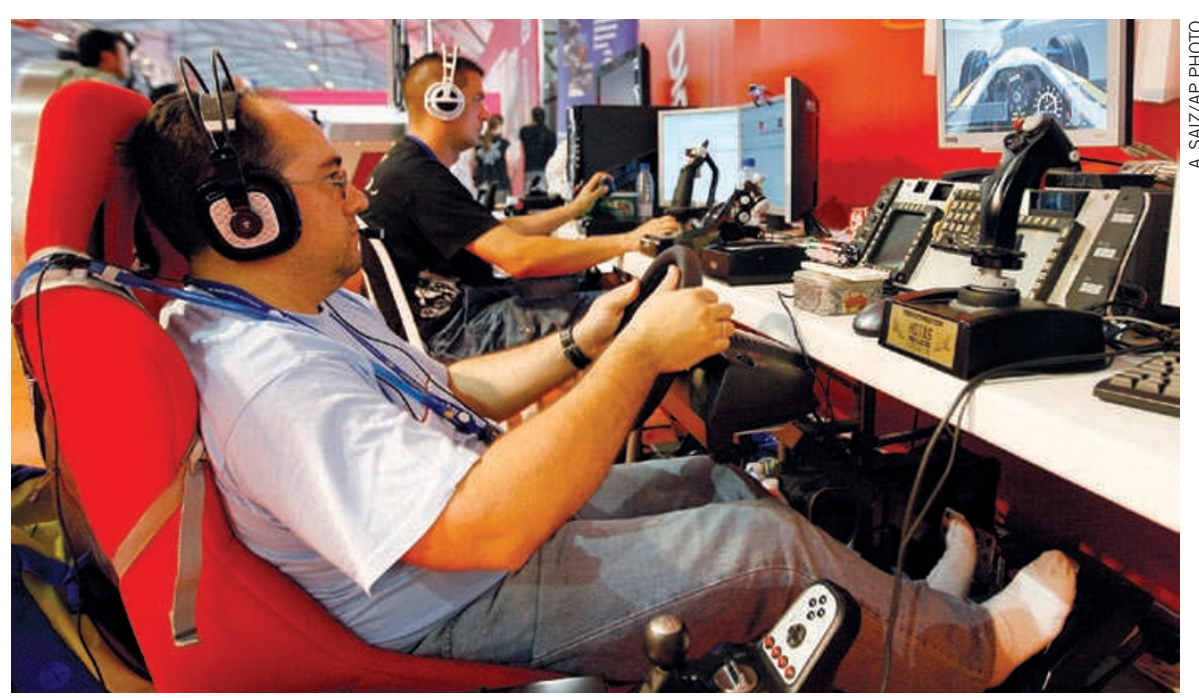

The mind's ability to adapt suggests that it can cope with our wired world — for better or worse.

NEUROSCIENCE

\section{Browsing and the brain}

\section{Two books reach opposite verdicts on how the Internet affects us, find Daphne Bavelier and C. Shawn Green.}

$\mathrm{W}$ henever a new technology reaches a tipping point of popularity, questions soon follow about its effects on society. The rise of the Internet has provoked two books probing its impact on the human brain. The fact that the authors reach opposite conclusions, despite relying on the same scientific evidence, underscores how little research has been done on this topic.

Nicholas Carr's The Shallows laments the possibility that long-term Internet exposure will sap us of our capacity for contemplation. At the base of his argument is the fact that the human brain is remarkably plastic. Carr makes this point compellingly using a mixture of historical anecdotes and interviews with experts in the neuroplasticity field, such as Michael Merzenich and Eric Kandel.

Having established that brains are constantly reshaped by experience, Carr argues that changes induced by Internet use, such as greater brain activation during web browsing, may not be in our best interests. If the brain adapts completely to the frenetic nature of the Internet, he warns, we may lose our capacity for absorbing practices such as reading a book. He worries that we may lose the very essence of what makes us human.

Nick Bilton's I Live in the Future is much more optimistic. Humming with enthusiasm for the continuing Internet revolution, he argues that social and cognitive changes are an inevitable consequence of any major technological advance and that our new abilities cannot be put back in the box.
The Shallows: What the Internet is Doing to Our Brains/How the Internet is Changing the Way We Think, Read and Remember

NICHOLAS CARR

W. W. Norton/Atlantic Books: 2010. 276 pp./384 pp. $\$ 26.95 / £ 17.99$

I Live in the Future \& Here's How it Works: Why Your World, Work, and Brain are Being Creatively Disrupted

NICK BILTON

Crown: 2010. 304 pp. $\$ 25, £ 16.99$

Such tension is to be expected whenever new forces enter society. By analogy, Carr discusses historical fears that the written word would act as a replacement for memory, resulting in humans that were 'shallower thinkers. Bilton notes early worries that the freedom of travel offered by the railway would result in weakening moral standards. Both books review suspicions that most people would prefer to listen to a book than to read one, leading to concerns that the invention of the phonograph would kill the art of writing.

Is the Internet different? Bilton and Carr rely on the same scientific facts to argue persuasively for opposite positions. For example, functional magnetic resonance imaging studies show that Internet searches activate a larger network of brain areas than does simple text reading. Web browsing also requires additional types of mental processing evaluating hyperlinks to make navigational decisions and filtering photos, videos and menus. As a result, brain activation is greater during Internet searches in people who are 